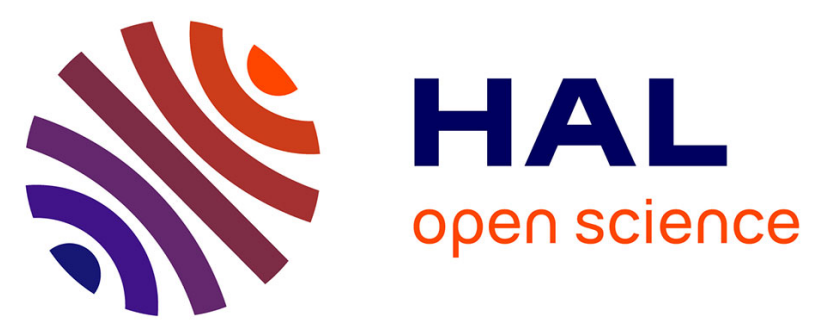

\title{
Visualisation of Gasoline and Exhaust Gases Distribution in a 4-Valve Si Engine; Effects of Stratification on Combustion and Pollutants
}

B. Deschamps, T. Baritaud

\section{- To cite this version:}

B. Deschamps, T. Baritaud. Visualisation of Gasoline and Exhaust Gases Distribution in a 4-Valve Si Engine; Effects of Stratification on Combustion and Pollutants. Revue de l'Institut Français du Pétrole, 1997, 52 (6), pp.651-667. 10.2516/ogst:1997065 . hal-02079137

\section{HAL Id: hal-02079137 \\ https://hal-ifp.archives-ouvertes.fr/hal-02079137}

Submitted on 25 Mar 2019

HAL is a multi-disciplinary open access archive for the deposit and dissemination of scientific research documents, whether they are published or not. The documents may come from teaching and research institutions in France or abroad, or from public or private research centers.
L'archive ouverte pluridisciplinaire HAL, est destinée au dépôt et à la diffusion de documents scientifiques de niveau recherche, publiés ou non, émanant des établissements d'enseignement et de recherche français ou étrangers, des laboratoires publics ou privés. 


\section{B. DESCHAMPS and T. BARITAUD}

Institut français du pétrole ${ }^{1}$
VISUALISATION DE LA RÉPARTITION DU CARBURANT ET DES GAZ BRÛLÉS DANS UN MOTEUR À 4 SOUPAPES À ALLUMAGE COMMANDÉ ; EFFET DE LA STRATIFICATION SUR LA COMBUSTION ET LES POLLUANTS.

Une méthode indirecte pour cartographier les gaz brûlés dans un moteur à allumage commandé a été développée. Elle est fondée sur une visualisation à partir de la fluorescence induite par laser (LIF) du mélange air-carburant non brûlé et ensemencé avec du biacétyl. Les gaz brûlés provenant à la fois des recirculations internes et externes sont observés. Ce type de diagnostic est complémentaire des techniques de LIF utilisées pour observer la distribution du carburant. Ces mesures de concentration sont réalisées dans un moteur à 4 soupapes avec accès optiques, pour une gamme étendue de conditions opératoires. Celles-ci comprennent des variations des modes d'injection du carburant et des modes de recirculation des gaz brûlés, provoquant ainsi différents types de stratifications qui correspondent à des dégagements d'énergie et des émissions de polluants très distincts. Le niveau de "tumble" et l'emplacement de l'étincelle sont aussi modifiés. L'observation de la stratification telle qu'elle est réellement dans le moteur constitue un moyen pertinent pour expliquer ses performances. Les paramètres permettant d'optimiser les niveaux de $\mathrm{NO}_{\mathrm{x}}$ et d'HC peuvent en être déduits, de même que l'efficacité des stratégies de recirculation et d'injection du carburant. Les résultats des visualisations ont été confirmés par des mesures obtenues dans un moteur monocylindre muni d'une culasse conventionnelle avec la même géométrie de chambre de combustion.

VISUALISATION OF GASOLINE AND EXHAUST GASES DISTRIBUTION IN A 4-VALVE SI ENGINE; EFFECTS OF STRATIFICATION ON COMBUSTION AND POLLUTANTS.

An indirect method to map the burned gases in SI engine has been developed. It is based on visualisation by Laser Induced 
Fluorescence of the unburned mixture seeded with biacetyl. Both internally and externally recirculated burned gases are monitored. This diagnostic is complementary to the LIF technique applied to measure the gasoline distribution. These LIF gasoline and burned gases measurements are applied in a 4-valve optical access SI engine for a large range of operating conditions. These include variations of both fuel injection and burned gas recirculation modes causing different types of stratification leading to very distinct heat release and exhaust emissions characteristics. Tumble level and spark location are also modified. The observation of the actual stratification in the engine forms a sound basis explanation of the engine performance. Parameters allowing an optimisation of $\mathrm{NO}_{x}$ and $\mathrm{HC}$ levels can be inferred, and in particular the effectiveness of recirculation and fuel injection strategies. The conclusions are confirmed by measurements in a single engine cylinder conventional head with the same geometry.

\section{VISUALIZACIÓN DE LA DISTRIBUCIÓN}

DEL CARBURANTE Y DELOS GASES CONSUMIDOS

POR UN MOTOR DE 4 VÁLVULAS DE ENCENDIDO CONTROLADO ; EFECTOS DE LA ESTRATIFICACIÓN SOBRE LA COMBUSTIÓN Y LAS EMISIONES CONTAMINANTES

Se ha desarrollado un método indirecto para cartografiar los gases consumidos por un motor de encendido controlado. Este método se funda en la visualización a partir de la fluorescencia inducida por láser (LIF) de la mezcla aire-carburante no consumida y sembrada con biacetil. Se han observado los gases consumidos, procedentes tanto de las recirculaciones internas y externas. Este tipo de diagnóstico es complementario de las técnicas de LIF que se emplean para observar la distribución del carburante. Estas mediciones de concentración se aplican en un motor de cuatro válvulas con accesos ópticos, y ello para una amplia gama de condiciones operatorias. Estas últimas incluyen las variaciones de los modos de inyección del carburante y de los modos de recirculación de los gases consumidos, provocando de este modo diversos tipos de estratificaciones que corresponden a desprendimientos de energía y emisiones de contaminantes de muy diversa índole. También se han modificado el nivel de "tumble" y el emplazamiento de la chispa. La observación de la estratificación tal como se produce realmente en el motor constituye un modo pertinente para explicar sus resultados prácticos. Los parámetros permiten optimizar los niveles de $\mathrm{NO}_{\mathrm{x}} \mathrm{y}$ de $\mathrm{HC}$ pueden así ser debidamente deducidos, del mismo modo que la eficacia de las estrategias de recirculación y de inyección de carburante. Los resultados de las visualizaciones se han confirmado mediante mediciones obtenidas con un motor monocilíndrico provisto de una culata convencional, con la misma geometría de la cámara de combustión.

\section{INTRODUCTION}

Diluting the gasoline-air mixture with burned gas is an efficient way to reduce $\mathrm{NO}_{\mathrm{x}}$ emissions level in spark-ignition [1] as well as in diesel engines. It is well known that the formation of nitric oxides is highly dependent on the flame temperature. When recirculating exhaust gases, the unburned mixture is diluted with burned gases, reducing the peak burned gas temperature and as a result the $\mathrm{NO}_{\mathrm{x}}$ formation rates. Another method is to run the engine under lean conditions. However both methods affect combustion stability, entailing the problem of irregular ignition and slower propagation which results in additional unburned hydrocarbon emissions. For both methods it is necessary to favour ignition based upon distributions of fuel and burned gases.

It has already been shown that in a 4-valve engine with a pentroof chamber, fuel stratification in the direction parallel to the top of the roof can be achieved by injecting into only one of the two intake ports $[2,3$, 4]. Biacetyl-LIF combined with LDV and combustion analyses [4] showed that by coupling the effect of intense turbulence, moderate velocity at the spark and ignition on the rich side, the performance of the 4valves engine was greatly enhanced. A strong correlation level between the local mixture composition at the spark and the duration of the early phase of combustion was found for two turbulence intensities. Also, the early heat release was favoured by enhancing turbulence. Hence, the lean operating limit of the engine could be extended. This study demonstrated the potential offered by stratifying the charge for lean combustion. Nevertheless this earlier work needed to be extended by the studying the effect of stratified gasoline on $\mathrm{NO}_{\mathrm{x}}$ and $\mathrm{HC}$ emissions which could be increased by the propagation of the flame toward the very lean region. The effect of residual gas distribution might be important as well [5]. Also the other known possibility for reduction of $\mathrm{NO}_{\mathrm{x}}$ emissions without altering $\mathrm{HC}$ needs to be investigated: Exhaust Gas Recirculation (EGR). In a lean operating engine, there is a limit to EGR beyond which the combustion process is altered and additional $\mathrm{HC}$ emissions and engine instability are expected. A possibility for improving tolerance to recirculation might be to stratify the engine charge in burned gases while stratifying the gasoline in the opposite way [6] and [7]. One can imagine that stratification in the burned gases might be also accomplished by recirculating a part of the exhaust gas into one of the two ports for stratifying gasoline. 
This study has been conducted to associate control of gasoline distribution and burned gases distribution in order to optimise the engine performance including emissions and tolerance to recirculation. In-cylinder burned gas measurements employing laser sheet excitation require the presence of markers in the burned gases. Water and $\mathrm{CO}_{2}$ are naturally present in combustion products. The concentration of burned gas has been measured locally using CARS applied to $\mathrm{CO}_{2}$ [8]. Recently water has been used to visualise the residual gas by PLIF with an eximer laser as a light source [9]. We decided to visualise the unburned mixture fraction from which we deduced burned gas fraction: the concept was to visualise fuel on one side and air on the other side. The complementary image reveals the burned gas distribution. The aim of the present work is to develop an optical diagnostic able to characterise the burned gas distribution in order to test possible solutions of exhaust gas recirculation for reducing emissions without altering combustion.

\section{RUNNING ENGINE CONDITIONS}

The test engine is a 4-valve pentroof chamber single cylinder described in earlier work1 [10] and [4]. Its geometrical characteristics are similar to the production engine, despite the presence of optical ports (Table 1). The operating speed was 1200 RPM and the volumetric efficiency in unburned mixture was regulated to 0.6. The ignition was activated $25 \mathrm{CAD}$ before the top dead centre (TDC). With the convention of TDC at $360 \mathrm{CAD}$, the intake valves open at $681 \mathrm{CAD}$ and close at $245 \mathrm{CAD}$. The fuel injectors were mounted in the intake ports, so they pointed directly at the back, upstream side of the valves. The timing of fuel injection and duration, ignition, and data acquisition are controlled by a computer. The synchronisation to the engine is achieved with the use of a crankshaft angle encoder. The engine is connected to an electric motor for keep the engine speed constant.

TABLE 1

Geometrical characteristics of the engine (in bold the compression ratio for the transparent engine)

\begin{tabular}{l|c}
\hline Displacement & $441 \mathrm{~cm} 3$ \\
Bore & $82 \mathrm{~mm}$ \\
Stroke & $83.5 \mathrm{~mm}$ \\
Compression ratio & $9.5 / \mathbf{8 . 4}$ \\
Rod/Half stroke ratio & 3.45 \\
\hline
\end{tabular}

The geometry of the studied engine allows different possibilities for varying the flow, injection and recirculation configurations.

\subsection{Flow configurations}

In the standard configuration, the 2 intake valves together with the pentroof combustion chamber lead to a flow pattern with a major rotating component around an axis parallel to the top of the roof (tumble $\mathrm{X}$ ) with significant flow motions remaining in other directions. A description of the flow field has been given by Le Coz et al. [10] using three-dimensional computations and measurements. Earlier work showed that the tumble component is accentuated by welding $180^{\circ}$ shrouds on the back of the intake valves. With this configuration, the flow pattern is composed of a stronger tumble $\mathrm{X}$ that increases while the piston is rising until destruction into small turbulent eddies and resulting in higher turbulence level at TDC.

\subsection{Intake configurations}

The 2 intake valves allow either homogeneous or stratified gasoline operations, depending on the injection mode (injecting into both intake ports or a single port respectively). The injection is initiated at $250 \mathrm{CAD}$ and lasts $38 \mathrm{CAD}$ (for dual ports injection) or $60 \mathrm{CAD}$ (for single port injection) to obtain a stoichiometric mixture. A $\lambda$-probe in the exhaust allowed verification and adjustment of the equivalence ratio by regulation of the fuel injection duration.

\subsection{EGR System and emission control}

A return line was welded between the tail pipe and the intake duct. For a better control of the EGR, hot exhaust gases were water-cooled before being introduced in the intake system. Thus, most of the water in the recycled exhaust gases was condensed and did not enter the combustion chamber. A thermocouple gave the temperature after the heat exchanger which was regulated to the temperature of the admitted flow (between $24^{\circ}$ and $26^{\circ} \mathrm{C}$ ). By cooling the exhaust gas we ensured the intake temperature was approximately constant over the set of experiments. The cooled exhaust gases were introduced either at a point upstream of the $\mathrm{Y}$ separation of the intake duct, or into only one intake duct. To control the EGR rate, two $\mathrm{CO}_{2}$ 
concentration analysers were installed in the system. The first one measured the molecular $\mathrm{CO}_{2}$ fraction in the exhaust, whereas the second one gave the $\mathrm{CO}_{2}$ fraction in the intake duct. $\mathrm{NO}_{2}$ and $\mathrm{HC}$ concentrations were also measured. Figure 1 illustrates the experimental setup for the exhaust gas recirculation and control methods.

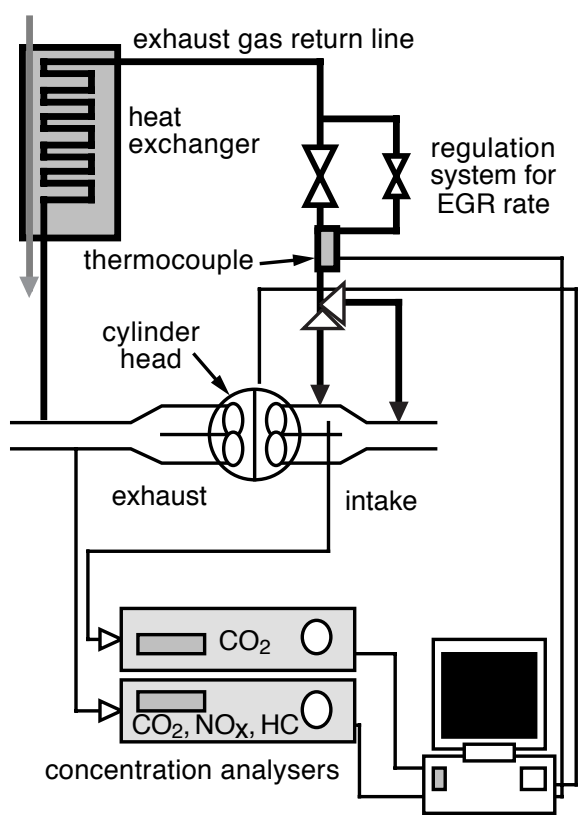

Figure 1

Sketch of the exhaust gas recirculation system with the measuring devices.

The EGR rate is defined as the volumetric fraction of recirculated exhaust to the total intake flow. Hence we are able to determine the EGR rate as:

$$
\eta_{\mathrm{EGR}} \approx \frac{1}{2} \frac{\left(\varepsilon_{\mathrm{CO}_{2}}\right)_{\mathrm{ADM}}}{\left(\varepsilon_{\mathrm{CO}_{2}}\right)_{\mathrm{ECH}}} \text { or } \frac{\left(\varepsilon_{\mathrm{CO}_{2}}\right)_{\mathrm{ADM}}}{\left(\varepsilon_{\mathrm{CO}_{2}}\right)_{\mathrm{ECH}}}
$$

where $\left(\varepsilon_{\mathrm{CO}_{2}}\right)_{\mathrm{ADM}}$ and $\left(\varepsilon_{\mathrm{CO}_{2}}\right)_{\mathrm{ECH}}$ are the volumetric fraction of $\mathrm{CO}_{2}$ in the intake and the exhaust ducts respectively. When using 2 intake ducts for recirculating, the equi-distribution of $\left(\varepsilon_{\mathrm{CO}_{2}}\right)_{\mathrm{ADM}}$ in two ducts was verified. The difference was less than $0.5 \%$. The output signals of the analysers are transmitted to the test computer, which allows monitoring and regulating the EGR rate, a valve system being mounted downstream of the heat exchanger.
It is important to point out that while recirculating the exhaust gases, the mass flow rate of admitted air was kept constant since the volumetric flow of fresh air into the cylinder was regulated by sonic orifices. The volumetric efficiency defined as the ratio of the mass of admitted gases to the mass of gases that corresponds to an entire fill-up of the cylinder depends on $\mathrm{h}_{\mathrm{EGR}}$. For experiments with EGR the modified volumetric efficiency $l_{\mathrm{EGR}}$ can be easily related to the volumetric efficiency relative to admitted unburned mixture la and $\mathrm{h}_{\mathrm{EGR}}$ as defined previously:

$$
\lambda_{\mathrm{EGR}}=\lambda_{\mathrm{a}} * \frac{1}{1-\eta_{\mathrm{EGR}}}
$$

This relation was verified experimentally for $h_{E G R}$ varying from 0 to $25 \%$.

Note that when recirculating exhaust gases, it is the total burned gas fraction in the cylinder that acts as a dilutent. These burned gases consist in residual gases from the previous cycle and exhaust gas recirculated to the intake. Residual gases are not taken into account by $\mathrm{CO}_{2}$ analysers.

\subsection{Spark plug configurations}

To take advantage of the in-cylinder stratification, we also had to optimise the spark plug location, based on a trade off between a good initial combustion phase and the wall vicinity. When stratifying the gasoline, the spark plug and the pressure transducer locations (originally $35 \mathrm{~mm}$ away from the centre in a direction parallel to the roof ridge) were permuted in order to favour the ignition process. Deschamps et al. [4] have shown that tumble motion in the offset spark plug case is favourable for flame initiation since the low velocity $(1-2 \mathrm{~m} / \mathrm{s})$ at the ignition angle (335 CAD) does not project the flame kernel on to the wall and since the higher but moderate turbulence levels for the strong tumble configuration also favours ignition.

\section{NEGATIVE PLIF METHOD FOR BURNED GAS VISUALISATION}

The visualisation technique in the present study is derived from the fuel concentration method presented in previous work and is based on planar laser induced fluorescence of biacetyl [11]. A frequency tripled YAG laser sheet $(355 \mathrm{~nm}) 25 \mathrm{~mm}$ wide is introduced in the 
combustion chamber in the direction of the pentroof ridge $4 \mathrm{~mm}$ below the spark plug. The air is seeded with biacetyl which fluoresces when excited with the YAG laser. The biacetyl burns so that no fluorescence can be observed in the burned gas. During the low pressure part of the cycle, a fraction of the burned gases remains in the combustion chamber. After the intake phase the mixture in the engine is composed of unburned gases seeded with biacetyl and residual burned gases without biacetyl. The locations where the intensity is lower reveal the presence of residual gas. A camera collects the fluorescence image through a quartz piston via a $45^{\circ}$ inclined mirror placed underneath the combustion chamber (Fig. 2). The image is a $21 \times 53.5 \mathrm{~mm}$ rectangle digitised to $112 \times 240$ pixels. Image calibration is achieved using the fluorescence image of a homogeneous mixture seeded at the same rate during a cycle with no residual gas (reference image). Using reference images, unburned mixture images and background images, the averaged unburned mixture image is divided by the average reference image after correction from the background, gain of the camera and laser intensity. The division by the reference also corrects for spatial imperfection of the laser profile and camera distortions.

The burned gas image is finally obtained by subtraction from unity (justifying the "negative PLIF" designation).

The accuracy of this method strongly depends on a good choice for the reference as well as the quality of the seeding system. To guarantee of a homogeneous distribution of the biacetyl in the intake air, a part of the air was diverted through a biacetyl seeding system. The seeded air (approximately 1.5\% biacetyl) was introduced far upstream of the intake valves insuring a homogeneous distribution of the biacetyl in the intake air. We verified the perfect spatial homogeneity. Since the seeding system worked on a carburetor basis, the quantity of biacetyl in the air depended on the air pressure in the seeding vessel and thereby on the pressure in the intake system. The intake pressure was monitored so that the pressure in the biacetyl vessel was the same for the reference images and the images containing residual gas.

The negative PLIF method was applied, with normal operation or with skip firing, with propane or iso-octane as a fuel, and with or without EGR.

When running the engine normally the reference was acquired before and after cycles with residuals. An example with propane as a fuel is given on Figure 3.

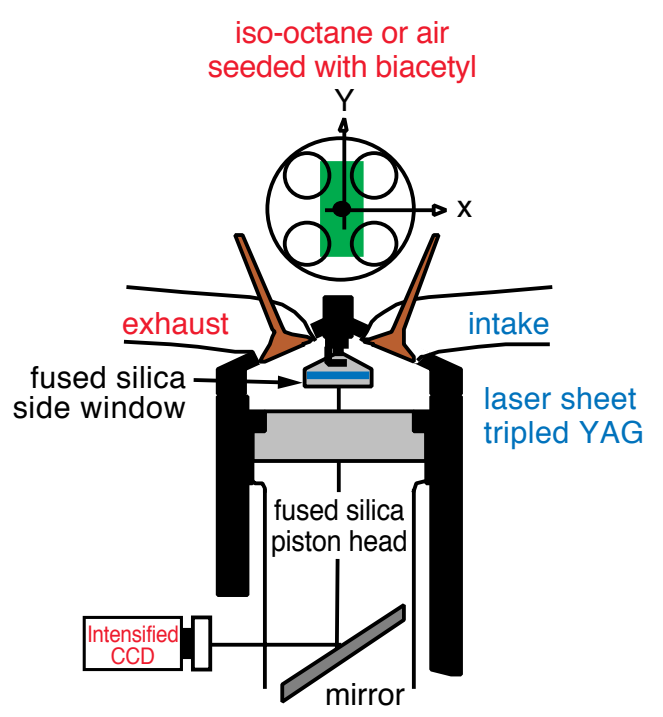

Figure 2

Engine description.

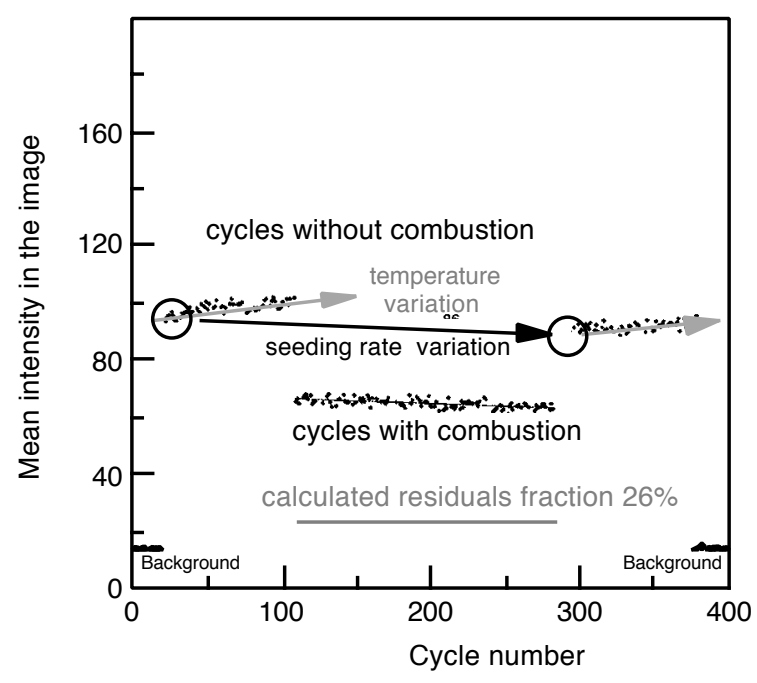

Figure 3

Mean intensity in the image versus cycles corresponding to a percentage for the calculated residual fraction (110 mbar pressure blockage, normal firing).

For this condition an exhaust blockage was applied to enhance residual gas concentration. 90 reference images (high signal) were acquired before and after 180 images with residuals (lower signal). The images 
are acquired $2 \mathrm{CAD}$ prior to the spark activation angle. During the acquisition of images, the engine is not fired and temperature decreases. This results in an increasing fluorescence signal as shown in Figure 3 (as fluorescence intensity increases when temperature decreases). The fluorescence intensity for images acquired with residuals (cycle with combustion) decreases slightly due to biacetyl level variations in the seeder. As can be seen, the seeding rate variation between the two sets of reference images follows the same slope as for images acquired with residuals. As the seeding rate decreases constantly over time (less than 10 units of intensity for 1000 cycles) it is easily corrected. Only the first few images of each reference acquisition set are taken into account for the averaged reference (to avoid the temperature problem). The residuals fraction is calculated using the averaged reference image and reported constant on the figure $(26 \%)$.

Under skip firing operating conditions (1/5), the images containing reference information and residuals are successively at the same crank angle. Then 3 cycles followed with no combustion. The Figure 4 shows alternatively the mean intensity in the reference image (grey squares) and in the image with residuals (black points) versus the cycle number. The individual reference image preceding the image with residuals is used to calculate the absolute residual gases rate (lower black crosses). Only a small variation of $0.5 \%$ is noticed, which corresponds to a relative error of $3 \%$.

An exhaust blockage pressure was applied to test the sensitivity of the method in both operating conditions (for propane as fuel). In Figure 5, one can see that the residual gas fraction increases with exhaust pressure, which is quite consistent, and more residual gas are detected with normal firing. Under skip firing conditions at 80 mbar two acquisition sequences lead to residual gas rate of $19.6 \%$ and $19.4 \%$ respectively. At 110 mbar $21.0 \%$ and $21.2 \%$ values were measured. This shows a good relative repeatability of the measurements.

When iso-octane is used as fuel, measurement of the mean burned gas distribution also requires the knowledge of the mean fuel concentration in addition to the mean air concentration. The acquisition consists of recording a block of images for fuel distribution measurements (seeding the fuel with biacetyl, not the air) and a block of images for air distribution (seeding the air only with the same amount of biacetyl as for the reference). In each record 60 images of background

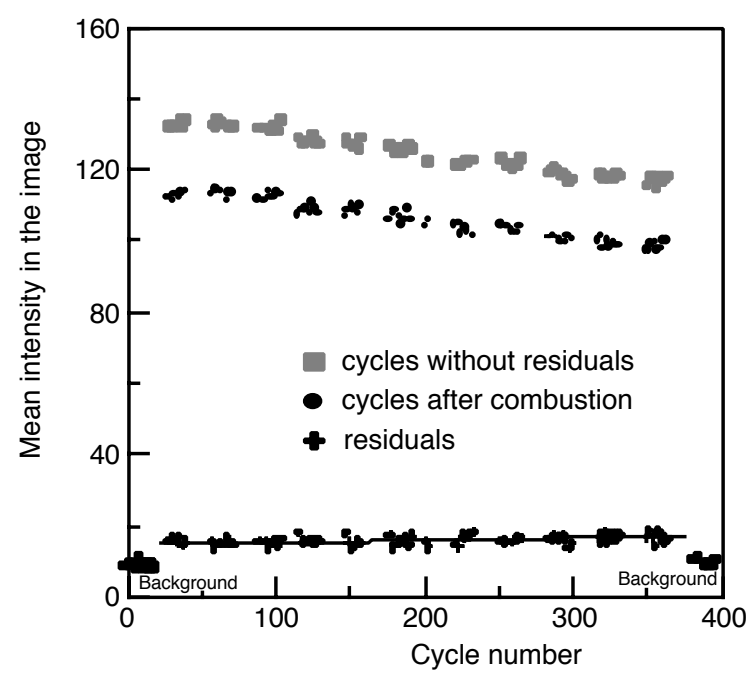

Figure 4

Mean intensity in the image versus cycles corresponding to a percentage for the calculated residual fraction (with no exhaust blockage (skip firing 1/5).

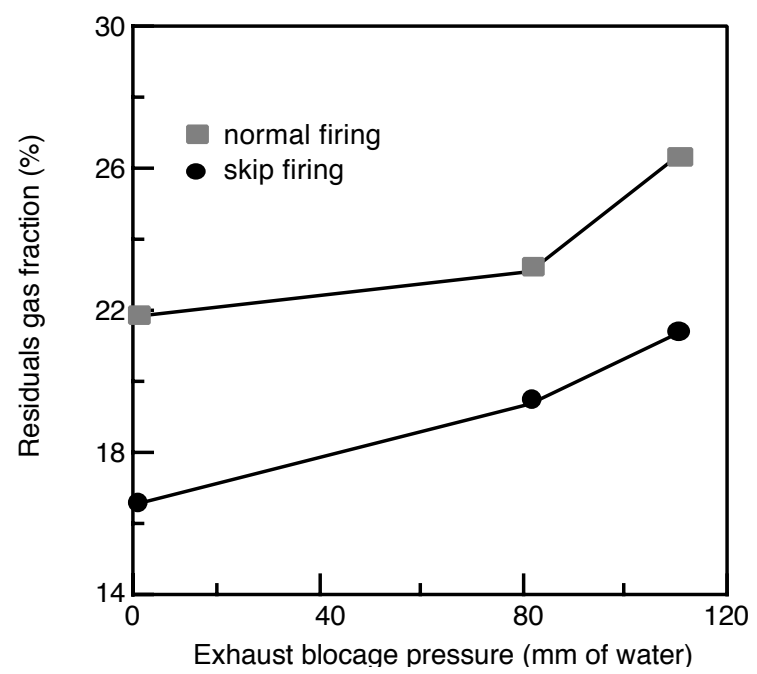

Figure 5

Exhaust blockage pressure effect on residual gas fraction ( skip firing, normal firing, enhanced tumble, volumetric efficiency $0.3, \phi=1$ )

(no biacetyl) and 60 reference images (no combustion, air seeded with biacetyl) are acquired. For each record, corrections for laser intensity and gain of the camera are applied. Then the average of background images, reference images and iso-octane or air images are obtained. Subtracting the background images and dividing by the reference image lead to the final 
concentration image of fuel or air. The obtained fuel concentration is normalised by setting the mean intensity equal to the concentration given by the lambda probe.

At the equivalence ratio $\phi$, vaporised iso-octane represents $0.0172 \phi$ liters. When a volume of air is admitted, $0.0172 \phi$ volume of iso-octane is injected. So the concentration of burned gas is given by the following equation:

$$
[\mathrm{BG}]_{\mathrm{xy}}=1-\mathrm{C}_{\mathrm{air}}[\mathrm{air}]_{\mathrm{xy}}^{\mathrm{norm}}-0.0172 \phi \mathrm{C}_{\mathrm{air}}[\text { fuel }]_{\mathrm{xy}}^{\text {norm }}
$$

$\mathrm{C}_{\mathrm{air}} \quad$ represents the mean air fraction in the image

[air] $]_{\mathrm{xy}}^{\text {norm }}$ the normalised distribution of air

[fuel $]_{\mathrm{xy}}^{\text {norm }}$ the normalised distribution of iso-octane

$\phi \quad$ is the equivalence ratio measured with the $\lambda$-probe.

Under EGR conditions (example on Figure 6), some cares must be taken regarding the reference image quality (related to seeding rate).

In the case of visualisation of residual gas without external recirculation, it is assumed that the burned gas in the real charge images is replaced by biacetyl seeded air in the reference images, so that the division of the two mean images gives the mean air fractions. This is not true when the exhaust gases are recirculated since the mass of gas in the combustion chamber is increased.

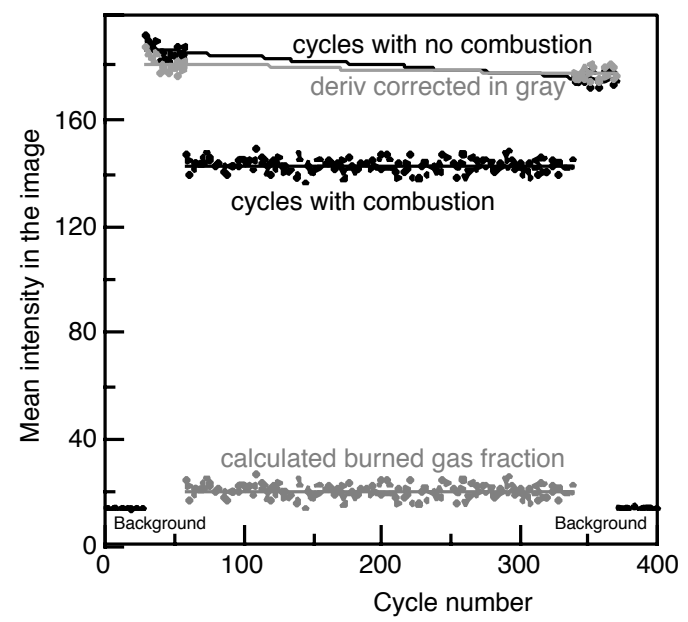

Figure 6

Mean burned gas fraction versus cycles with 15\% EGR (on black corrected images, on grey reference images intensity after correction of decreasing signal). Mean intensity corresponds to a percentage for the calculated residual fraction.
Also, as the recirculated exhaust gases increase the pressure in the intake system, the seeding rate for the EGR images is reduced compared to the corrected reference images which are acquired for a lower $l_{a}=0.6$. For this reason, the admitted air flow rate for the reference images is adjusted, so that the volumetric efficiency $l_{\mathrm{a}}$ corresponds to $\mathrm{l}_{\mathrm{EGR}}$ according to Equation (2). It is verified that by adjusting la to the appropriate value, the admitted pressure increased to the pressure measured with EGR so the seeding rate is also appropriate.

As long as the slope of the straight line, which connects the first set of reference images with the second one, corresponds to the decrease in intensity signal for the burned gas images, the mean image of the two reference image sets will give a mean reference image for the total of the burned gas images for quantification purposes. When running the engine with EGR, between 2 and 6 minutes passes between the acquisition of the reference images and the burned gas images to regulate the EGR rate. During this time the level in the biacetyl tank decreases reducing the seeding rate. To account for that, we have measured the time between the acquisition of the different image sets, i.e. first set of reference images - burned gas images second set of reference images. Subsequently the decrease in intensity signal with time was calculated in the image treatment from the burned gas images, for which we have also measured the acquisition time. The decrease in signal intensity between the acquisition of the different sets could then be calculated and correspondingly be added or subtracted from the reference image sets. This is shown in Figure 6, where a representative experiment with EGR is illustrated. As can be seen, this correction method improved the reliability of the measuring method.

Thus we have an optical diagnostic available for burned gas as well as iso-octane mean distribution studies. However, it is not possible to dissociate residual gas from recirculated exhaust gas or to evaluate a single cycle burned gas distribution. Also it is quite difficult to quantify the accuracy of the presented technique. Nevertheless, the measurements for the distribution of residual gases were repeatable. For experiments with EGR it turned out that the dependence of the seeding system on the operating conditions presented a problem which was rectified by acquisition procedures. 


\section{RESULTS}

\subsection{Residual gas}

As measured and described by Galliot et al. [5], the amount of residual gas in the cylinder depends on the exhaust and intake processes. In naturally aspirated engines, when the intake valve opens, there is a blowdown of the burned gas into the intake port, which goes back into the cylinder later on during the intake process. During the valve overlap period, there is also a reverse flow of the burned gas from the exhaust ports into the cylinder. The amount of residual gas trapped in the cylinder therefore decreases with increasing intake pressure. With the presented technique a series of engine operating points with propane or iso-octane injection in the two intake ducts were performed. The image acquisition angle was constantly $333^{\circ} \mathrm{CA}$. Different parameters which influence residual gas concentration were investigated: fuel, injection configuration, flow, volumetric efficiency, and spark plug location.

\subsection{Influence of fuel: propane/iso-octane}

Residual gas distributions obtained by running the engine with propane or iso-octane for the reference with a central spark plug and a volumetric efficiency $1_{a}$ of 0.6 are given in Figure 7 . The average residual gas fraction for propane $(12.3 \%)$ is lower than for iso-octane $(14.3 \%)$ octane $(14.3 \%)$. This is explained by the fact that the combustion process of propane and iso-octane are different. This influences the pressure in the intake system and thus the mean residual gas fraction. In both cases the residual gases are concentrated in the middle and, particularly for the iso-octane case, on the intake side. This distribution can be explained by the large tumbling motion on the exhaust side of the combustion chamber, being responsible for a good mixing process between the residual gases and the intake air, and the small vortex on the top of the intake side, which on the contrary makes the mixing of the residual gases with fresh air more difficult. In previous work [4] it was also remarked that the mixing of fuel with air was more difficult in the middle of the chamber. This can explain that the distribution of residual gases for an engine operating with propane is flatter than for iso-octane since propane/air mixing is perfectly homogeneous.

To summarise flow and fuel distributions appear to be important parameters for residual gas distribution.

\subsection{Effect of iso-octane distribution on residual gas}

Figure 8 confirms the effect of fuel distribution on residual gas. The normalised fuel distribution is reported on the top of the figure for injecting through 1 or 2 intake ducts and the corresponding residual gas profiles plotted on the bottom show opposite trends. A stratification in fuel of $20 \%$ produces a reverse stratification of residual gas of $10 \%$.

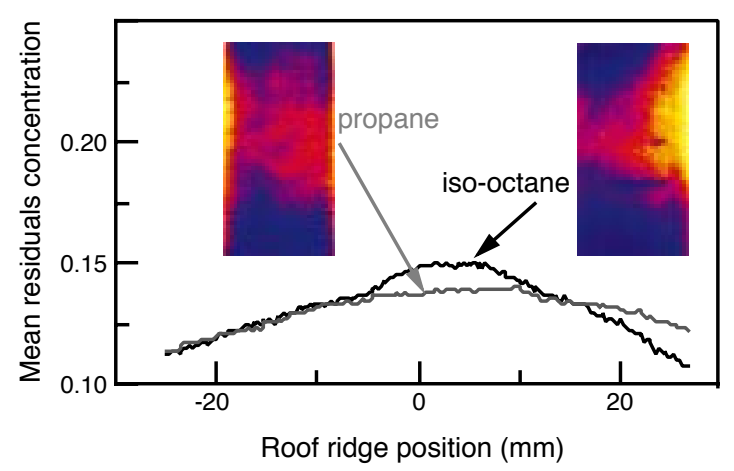

Figure 7

Residual gas distribution for: propane (left) and iso-octane (right) for a central position of the spark plug and a volumetric efficiency $\lambda_{a}=0.6$. Intake is on the right on the image

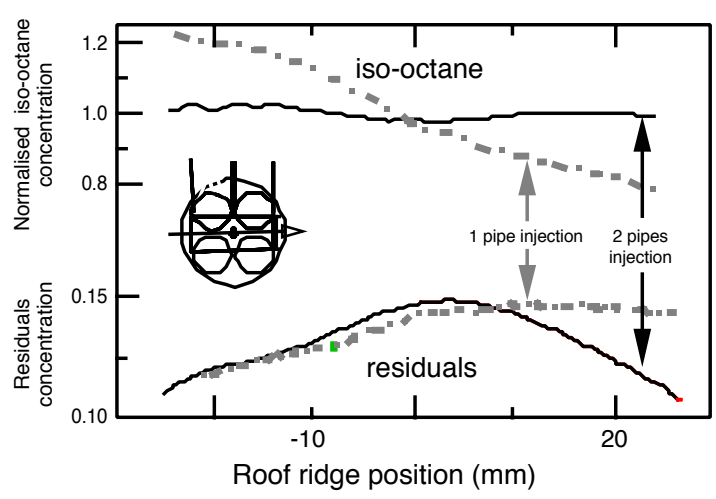

Figure 8

Residual gas distribution (injection for 1 or 2 intake ducts). 


\subsection{Effect of enhanced tumble on residual gas}

The residual gas distribution results from its motion from intake to compression. It is interesting to visualise their organisation during these phases in standard and enhanced tumble configuration. This experiment was made with propane to avoid fuel distribution effects. Figure 9 shows burned gas distribution during intake stroke (standard on top/enhanced tumble on bottom). Images are normalised by their mean intensity for gradients to be enhanced. One can see the unburned mixture (blue) entering the cylinder between the 2 intake ducts located on the right and mixing with residual gas from the beginning of the intake process to the BDC. The highest velocity in the tumbling direction is between the 2 intake valves. One can notice that the mixing between unburned mixture and residual gas is more difficult in the roof ridge direction for the enhanced tumble case. This is due to the large velocity in the perpendicular direction for this condition. However, during the compression stroke the increased turbulence induced by the destruction of the tumble leads to increased mixing of residual gas in the roof ridge direction.

Figure 10 depicts the mean, minimum and maximum burned gas fraction in the image during the intake and compression stroke for both configuration. This figure shows the difference in mixing of residual gas with air
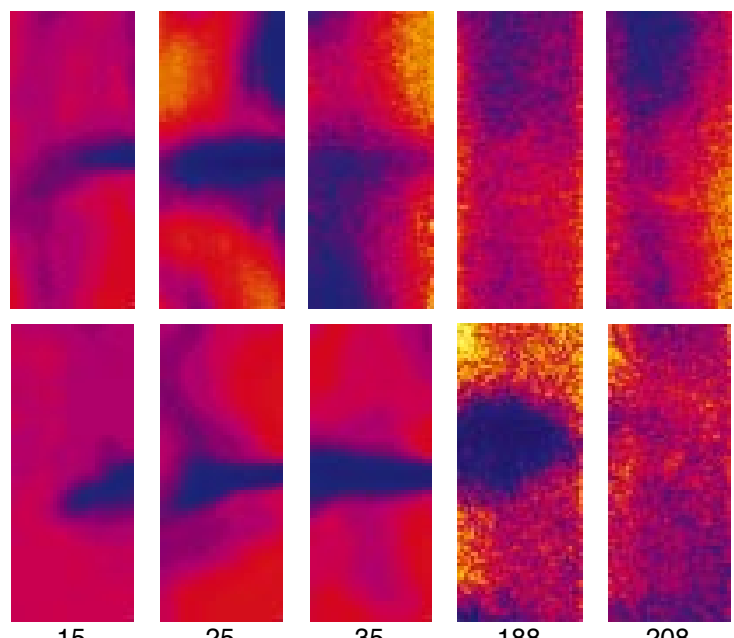

15

25

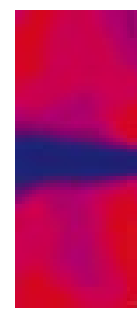

35

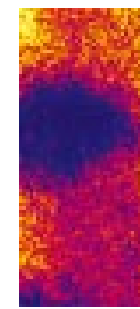

188

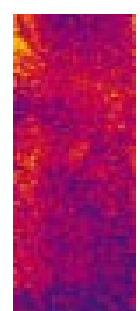

208

Figure 9

Burned gas distribution during intake stroke (standard on top/enhanced tumble on bottom).

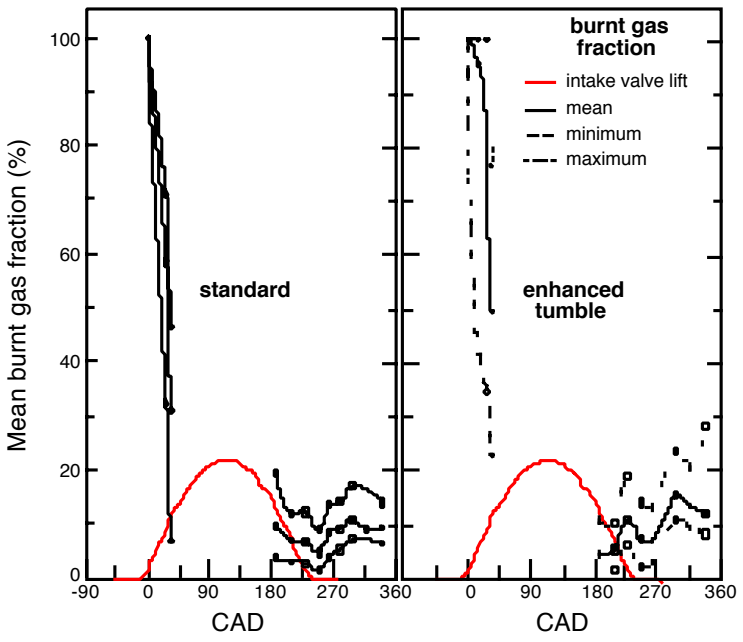

Figure 10

Burned gas fraction during intake and compression stroke (standard/enhanced tumble).

between the two flow configurations. For the reference case, the minimum, maximum and mean burned gas fraction strongly decrease as soon as the intake valves open. At 190 CAD unburned gases have filled the cylinder, burned gas remains around intake valves because of the tumble dragging the residual gas which were near the bottom of the intake part of the combustion chamber. The velocity level is lower because of the reverse motion of the piston. No more unburned gas will be admitted, the piston rises and one can see the burned gas fraction level fluctuating as it is carried along by the flow. In the enhanced tumble case, the maximum remains at $100 \%$ during $30 \mathrm{CAD}$ while it has already decreased by $71 \%$ in the standard case. Also the minimum and mean burned gas fraction (in the image) is higher than for the standard case. This is explained by a more directed flow field in the tumble case. When the piston rises, the burned gas globally increases showing that during the intake process, burned gas had accumulated in the bottom of the cylinder. An oscillating phenomena appears with a period of $70 \mathrm{CAD}$. A simple calculation based on the time it take to a fluid particle to run over a diameter about half of the stroke determined a mean tumble velocity of about $13 \mathrm{~m} / \mathrm{s}$ (also measured by LDV during the compression stroke).

The experiments was performed with iso-octane (at $333 \mathrm{CAD}$ ) and residual profiles in the roof direction were compared for standard and enhanced tumble configurations on Figure 11. One can see that for the 
enhanced tumble case, the residual gases are more homogeneous because the turbulence is higher. The residual gases are also less concentrated due to the periodic phenomena of tumble or to the better combustion which leads to more pressure in the intake ducts.

\subsection{Effect of spark plug location}

When igniting the mixture at a position near the chamber wall, the residual gas distribution does not change significantly. As can be seen in Figure 12 where the residual gas concentration images for a central and an offset position of the spark plug with a volumetric efficiency of 0.60 are compared. The main fraction of the residual gas is again located in the centre and on the intake side.

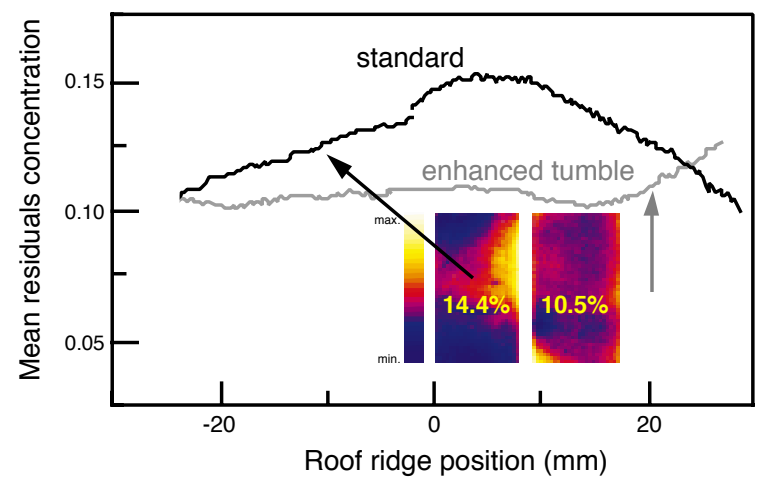

Figure 11

Residual gas distribution with central spark plug. Standard or high tumble conditions.

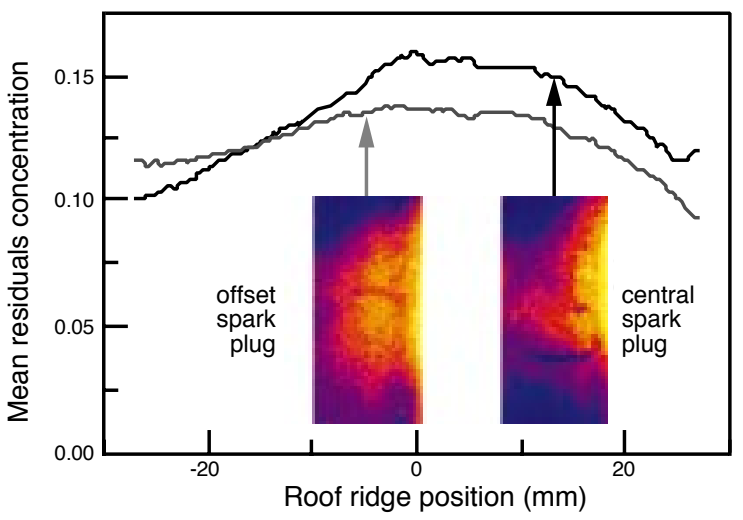

Figure 12

Distribution of residual gas for a volumetric efficiency $\lambda_{\mathrm{a}}=0.60$; offset spark plug on the left, centred on the right.
However, regarding the profiles, we see that for an offset position of the spark plug the distribution of residual gases is more even, and the average fraction is lower: $12.5 \%$ with regard to $14.3 \%$ for a central position. A partial explanation to this might be that the engine pressure during the outlet process, which proportionally influences the scavenging of the cylinder, was slightly higher for the offset position, as could be verified by the acquired pressure data.

\subsection{Effect of volumetric efficiency on residual gas}

By varying the volumetric efficiency, the residual gas distribution field for iso-octane changes significantly, as can be seen in Figure 13 for the standard configuration. For higher volumetric efficiency the main fraction of residual gases is still concentrated in a corridor between the exhaust and the intake side but clearly more towards the upper part of the image. This higher agglomeration of residual gases in one part of the imaged region might be explained by the increasing flow velocity, and gas density with increasing volumetric efficiency, which enhance a possible unsymmetrical in the velocity field. Le Coz et al. [10] and Deschamps et al. [4] have shown that the velocity field in the combustion chamber, due to marginal differences in the two intake ports, is far from being perfectly symmetrical. Table 2 shows that the average residual gas concentration decreases with increasing volumetric efficiency. This is due to the increase in pressure in the intake ducts for larger charges. Also one can see the combined influence of the volumetric efficiency and spark plug location which increases either intake or exhaust pressure.

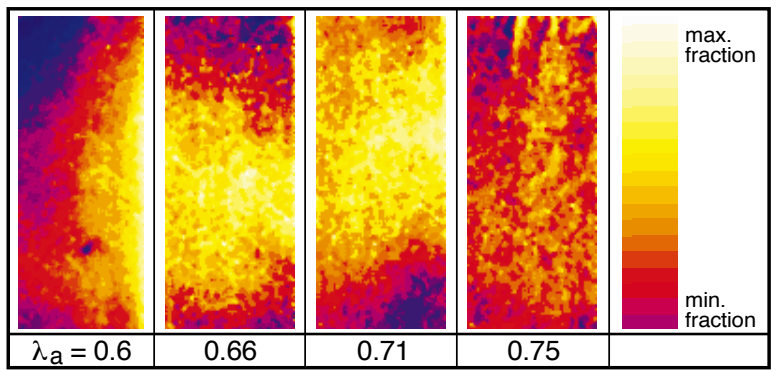

Figure 13

Residual gas distribution for different volumetric efficiencies $\lambda_{\mathrm{a}}$ and a central position of the spark plug. 
For $\lambda_{\mathrm{a}}=0.6$ less residual gases are present due to a larger exhaust pressure as already suggested. At higher volumetric efficiency, the offset spark plug leads to higher residual gas concentrations than in the central spark plug case.

TABLE 2

Variation of residual gas concentration with volumetric efficiency. Spark plug location effect

\begin{tabular}{c|c|c}
\hline $1_{\mathrm{a}}$ & Offset spark plug (\%) & Centred spark plug (\%) \\
\hline 0.30 & 26.9 & \\
0.50 & 13.4 & \\
0.60 & 12.4 & 14.4 \\
0.67 & 11.7 & 7.6 \\
0.71 & 9.8 & 5.4 \\
0.75 & 9.9 & 3.9 \\
\hline
\end{tabular}

The investigation of the residual gas visualisation has demonstrated that fuel distribution, flow, spark plug location and volumetric efficiency have important influences on their distribution. Residual gas concentration is a result of a complex combination of intake and exhaust pressure, flow motion and combustion processes. We verified that the amount of residual gases in the combustion chamber decreases for configurations which increase intake pressure or decrease exhaust pressure: volumetric efficiency influences intake pressure. The spark plug location influences the combustion process then the exhaust pressure, especially at high charge. Also it was found that the flow motion is responsible for the residual concentration at spark timing, especially when the tumble is enhanced as residual gas is trapped in the tumbling movement. Finally, residual gas distribution seems difficult to control because of the complex interaction between parameters. A solution would be to minimise residual gases and replace them by recirculated exhaust.

\section{EXTERNAL EXHAUST GAS RECIRCULATION}

The burned gas distribution is now composed of residual gases and recirculated exhaust gases, admitted with the fresh air.

\subsection{Injection by two ducts}

In a first approach fuel was injected by two ducts to study possibilities of stratifying burned gases by changing EGR configuration. EGR was introduced through two ducts with rates of 7.5 and $15 \%$, or one duct with a rate of $15 \%$. Burned gas concentration profiles in the roof ridge direction for the different EGR rates and configurations have been compared with residual gas (reference conditions) on Figure 14. When EGR is introduced through two ducts the distribution of burned gas is relatively equivalent to residual gas distribution (0\% EGR) but the mean concentration in the image increases when the EGR rises and is always greater than the EGR rate measured by $\mathrm{CO}_{2}$ analysers. This difference is due to residual gas presence. One can see that when recirculating exhaust gas through one duct, burned gases are stratified with a variation of $21 \%$ in the roof ridge direction. The steepest slope is encountered in the middle of the imaged plane. This corresponds to observations made by Deschamps et al. [4] for a horizontal fuel stratification with the same engine and flow configuration and in the same image plane.

We now know that it is possible to obtain homogeneous or stratified burned gas distribution whether the exhaust gases are recycled through two or only one duct respectively. We would like to study now the possibility of enhancing the stratification factor.

Figure 15 describes the burned gas distribution for different EGR rates (10.15 and 20\%) introduced through both intake ducts. Figure 16 shows the effect of EGR rate on burned gas concentration profiles for both

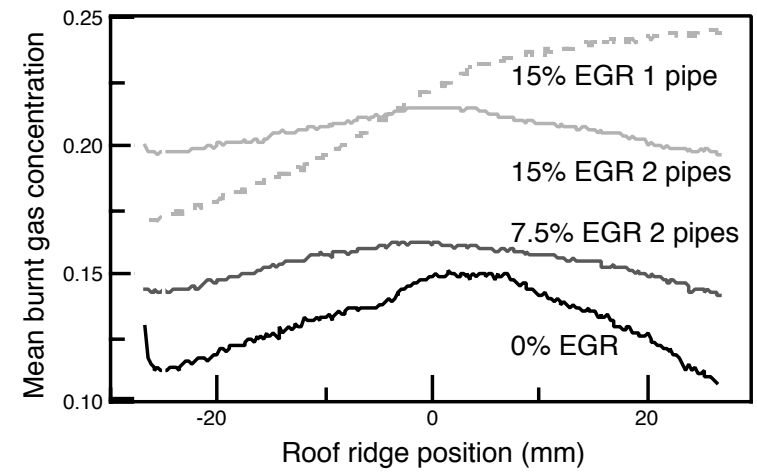

Figure 14

Burned gas concentration profiles for different EGR rates and configurations to be compared with residuals (standard conditions). 


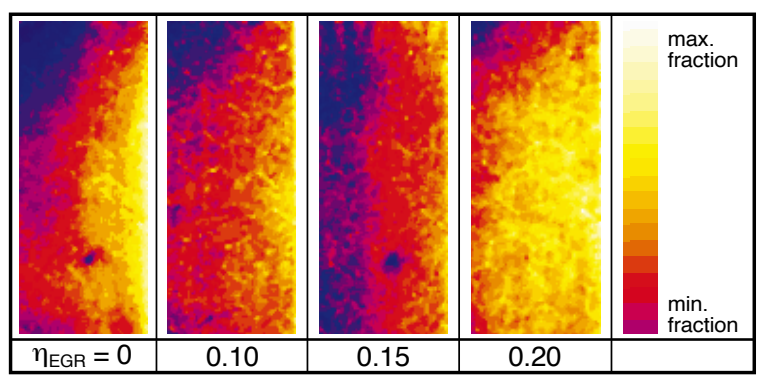

Figure 15

Burned gas concentration distribution for different EGR rates and configurations to be compared with residuals (standard conditions).

EGR configurations (reference conditions) and the effect of spark plug location on burned gas stratification. Figure 16a and 16a' show evidence that the burned gas distribution becomes more homogeneous when recirculating exhaust gas by both intake conducts. Note that the larger amount of burned gases is concentrated towards the side for which we have verified a higher agglomeration of residual gases.

When recirculating EGR through one duct, for a central position of the spark plug (Fig. 16b and 16b'), each of the three EGR rates leads to a clear stratification. The highest concentrations for all three EGR rates are not encountered at the upper end of the imaged region, but rather at a location, which corresponds to $+15 \mathrm{~mm}$ on our scale. This is more pronounced for the lowest EGR rate where residual gas concentrations are at their highest percentage at this location. For $15 \%$ and $20 \%$ EGR rates the stratification decreases because the contribution of residual gas decreases considerably (see Table 2 for corresponding $1_{\text {EGR }}(0.60 ; 0.667 ; 0.706 ; 0.750)$ to $\mathrm{h}_{\mathrm{EGR}}(0,10,15$ and $20 \%$ ). The stratification, which was about $27 \%$ for EGR rate $10 \%$ leads to $20 \%$ for $15 \%$ and $20 \%$ EGR.

For an offset spark plug residual gases were more homogeneous and less decreased at high volumetric efficiencies (corresponding to EGR rate, on Table 2). Burned gas stratification seems to increase with increasing EGR rates. For 10\%, 15\% and 20\% EGR rates the stratification factor is $12.5 \%, 15 \%$ and $22 \%$. The greatest slopes are again encountered in the middle of the imaged planes, but they are less steep compared to Figure 16b. The highest concentrations are encountered on the side of recirculating. The difference in the profiles for a central and an offset spark plug

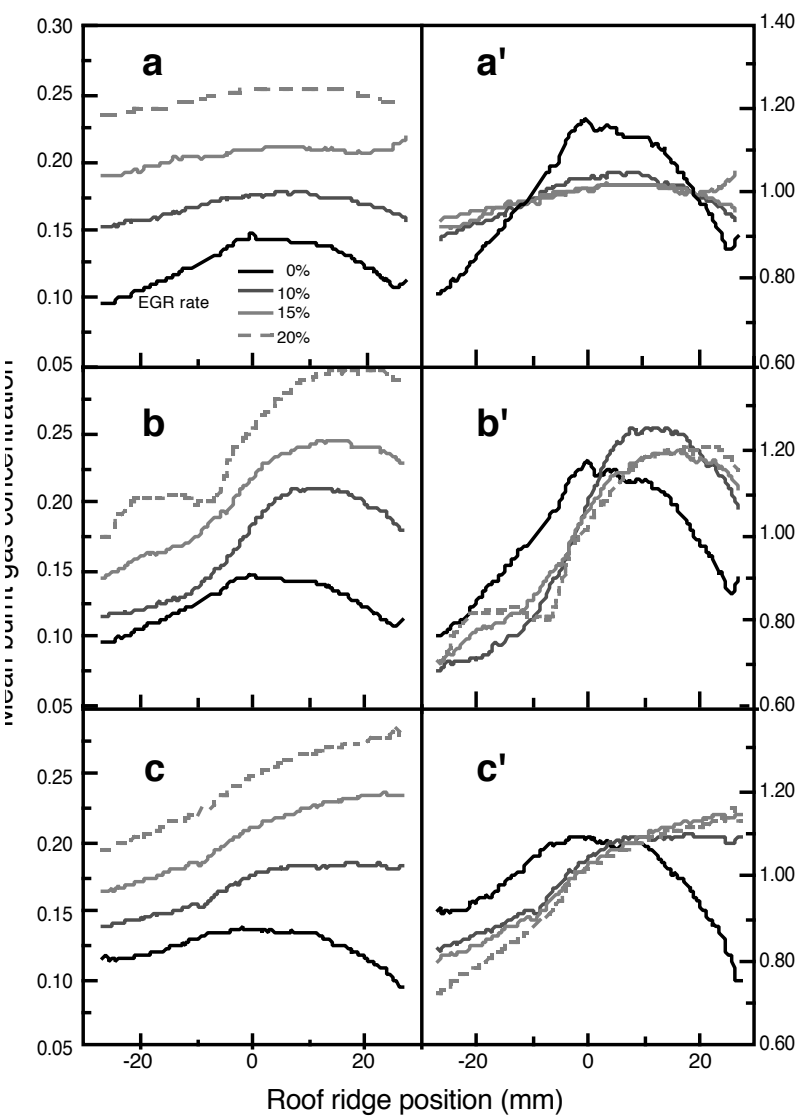

Figure 16

Burned gas concentration profiles for different EGR rates and configurations to be compared with residuals (standard conditions).

position are mainly due to differences in residual gas distribution. This difference vanishes when the EGR rate increases.

In fact while recirculating more exhaust gases, the contribution from residual gases decreases. This is consistent with getting a more homogeneous distribution of burned gas when recirculating through both intake ducts. Also one can compare the mean burned gas fraction in Figures $16 \mathrm{a}, \mathrm{b}$ and $\mathrm{c}$ and conclude that when recirculating, regardless of the configuration, as the EGR rate is increased the less variation there is in the mean burned gas fraction.

The residual gas contribution for an offset spark plug and different EGR rates through one duct are is presented in Figure 17. This figure compares the mean burned gas concentration measured in the image (1) to the concentration which should be measured if residual 


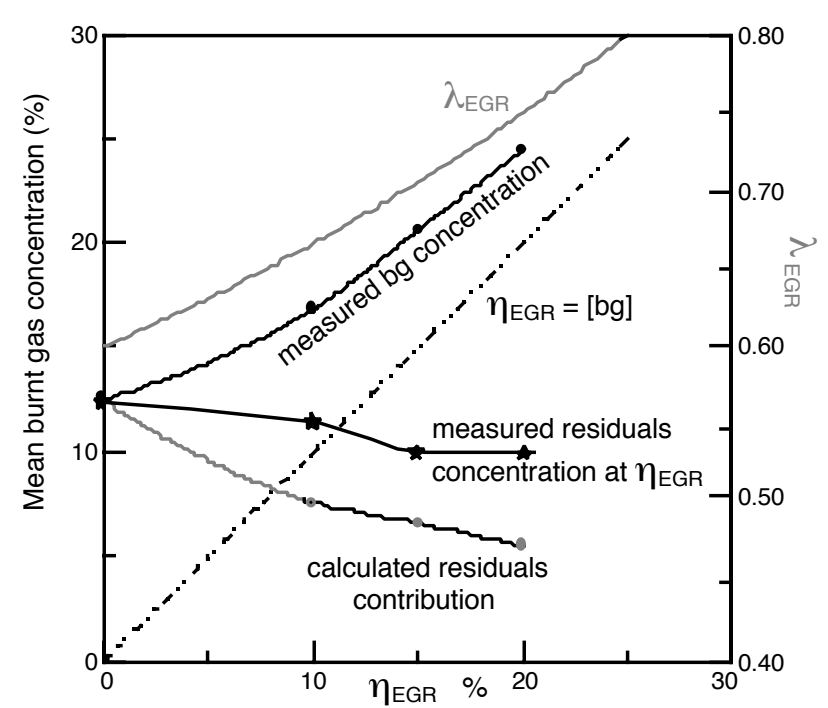

Figure 17

Comparison of measured burned gas concentration at EGR rate $\eta_{\mathrm{EGR}}(-\bullet-)$, and measured residuals (-*-) at equivalent volumetric efficiency $\lambda_{\mathrm{EGR}} \cdot \lambda_{\mathrm{EGR}}=\mathrm{f}\left(\eta_{\mathrm{EGR}}\right)$ and burned gas fraction $=\eta_{\mathrm{EGR}}$ also reported with the calculated residual contribution (--) following Equation (2). Standard conditions, EGR by one intake ports, offset spark plug.

gases were not present (2) $\left(\mathrm{h}_{\mathrm{EGR}}=\right.$ burned gas concentration). The gap between (1) and (2) should be due to presence of residual gas. The molar fraction of residual gas is easily deduced from measured burned gas fraction $x_{b g}$ and EGR rate following the Equation (4) which is drawn in Figure 17.

$$
x_{\text {res }}=\frac{x_{b g}-\eta_{E G R}}{1-\eta_{E G R}}
$$

The measured residual gas for volumetric efficiencies corresponding to the EGR rates are also plotted on Figure 17. One can see that the calculated residual gas contribution is smaller than measured residual gas. One can explain this by the fact that residual gases are measured in a plane while the calculation includes the entire chamber volume. Another explanation would be that EGR modifies combustion process and can lead to less residual gases. For the experiments without EGR the intake pressure can be estimated to be higher since the heat release and the engine pressure, which affect the intake conditions were higher. Therefore the mean residual gas fraction should be lower in the EGR conditions than the one measured at corresponding volumetric efficiencies. The recirculation of exhaust gas scavenges the engine in the sense that the amount of residual gases is considerably reduced. Now we can say that it is possible to produce homogeneous burned gas distribution when recirculating EGR through both ducts and to stratify them when recirculating through one duct. As the rate of recirculation is increased, the more controlled the burned gas distribution will be since the residual gas distribution vanishes.

By enhancing the tumble a stratification of $23 \%$ in burned gas is amplified to $33 \%$ as shown on Figure 18 for $15 \%$ EGR.

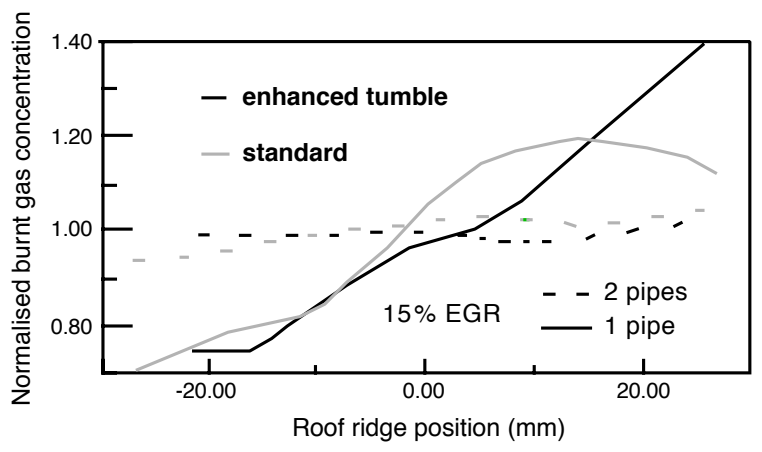

Figure 18

Effect of enhancing tumble on burned gas stratification.

\subsection{Injection by one duct}

By injecting fuel into only one of the two intake ducts when stratifying the engine charge with burned gas, a complementary fuel stratification can be achieved. Injecting fuel in the duct opposite to the recirculation one amplifies the stratification (Fig. 19). Moreover a homogeneous distribution of burned gas can be achieved when recirculating EGR through the injecting duct. Figure 20 shows that 3 levels of stratification are obtained $0,7.5 \%$ and $17 \%$ respectively when recirculating in the injecting duct, in both or the opposite duct.

Burned gas stratification control is achieved by a combination of favourable parameters: maximum recirculation in one duct, injection in the opposite pipe, and enhanced tumble. Homogeneous distribution of burned gas is obtained when recirculating exhaust gases 


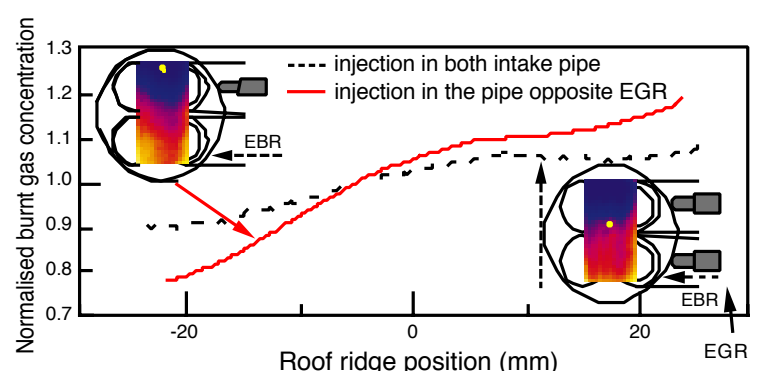

Figure 19

Effect of fuel stratification on burned gas distribution.

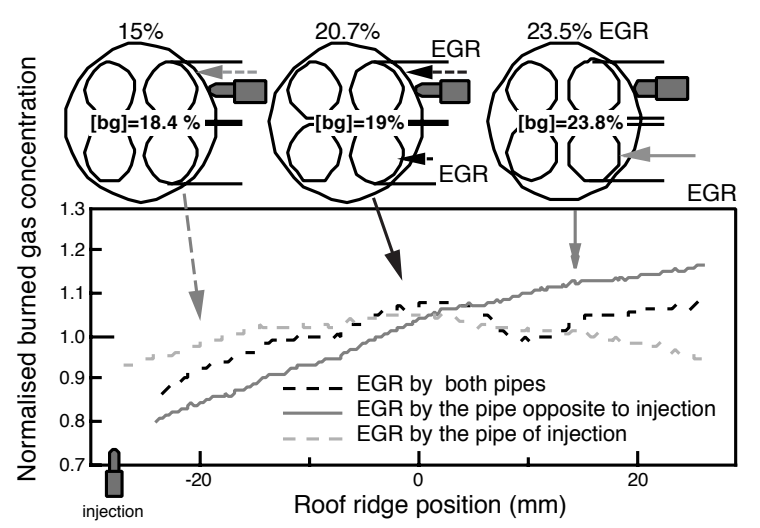

Figure 20

Effect of EGR configuration on burned gases distribution and fraction $([\mathrm{bg}])$. Fuel is injected by one duct.

and injecting fuel in both intake pipes or when recirculating exhaust gases and injecting fuel in the same intake pipe. The higher the EGR rate, the better the distribution of burned gases can be controlled.

\subsection{Tolerance to EGR}

Tolerance has been determined with a stability criterion of MEP of 0.07 for all possible combinations of EGR, injection, spark plug location and flow configurations at optimum spark advance. Three key parameters emerge from tolerance results reported on Figure 21 along with $\mathrm{NO}_{\mathrm{x}}$ emissions: flow field, recirculation configuration and fuel concentration at ignition location. Enhanced tumble, stratified fuel distribution (with favourable spark location) and recirculating exhaust gas in two ducts favour recirculating capabilities. The configuration which meets the 3 favourable conditions referred as $\mathrm{B}$ is the

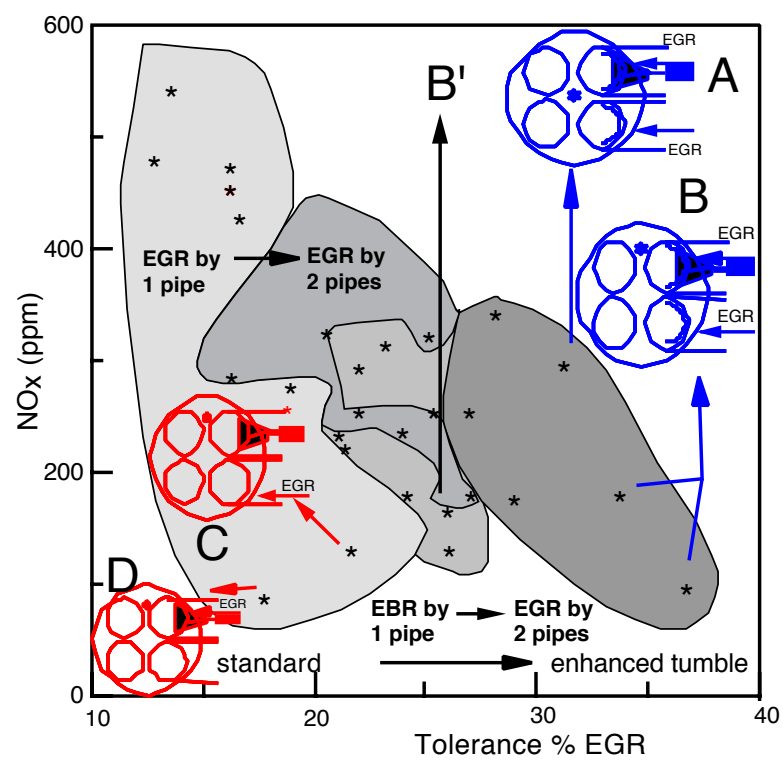

Figure 21

Effect of exhaust gas and flow configurations on tolerance and $\mathrm{NO}_{\mathrm{x}}$ emissions.

most tolerant configuration (35\% for stoichiometry and $31.5 \%$ at an equivalence ratio of 0.8 ). The same configuration except central spark plug (referred as A) was also very favourable (29\%). In standard flow field, the $\mathrm{B}^{\prime}$ configuration analogous to B takes up to $24.5 \%$ and $25.7 \%$ at respective equivalence ratio 0.8 and 0.9 . Configuration $\mathrm{C}$ with recirculation and injection in opposite intake pipes tolerates $23 \%$ while configuration $\mathrm{D}$ combining recirculation and injection in the same intake pipe does not take more than $17 \%$ EGR. To our knowledge, configuration $\mathrm{D}$ is the most homogeneous in term of burned gas distribution and configuration $\mathrm{C}$ the most stratified for standard flow cases. D is more difficult to ignite than $\mathrm{C}$ because of a lack of oxygen. We did not find any reason for configuration $\mathrm{B}^{\prime}$ being more tolerant except that homogeneous burned gas distribution implies a better cycle to cycle stability for an ignition or flame propagation.

\subsection{Emissions}

Without recirculation (Fig. 22), enhancing the tumble increases $\mathrm{NO}_{\mathrm{x}}$ emissions: a high temperature at the end of the combustion phase adds further to a lower dilution by residual gas. Igniting combustion near the wall, the flame rapidly hit the wall reducing flame interface and increasing thermal transfer so $\mathrm{NO}_{\mathrm{x}}$ emissions are reduced. Also we noticed that igniting in 


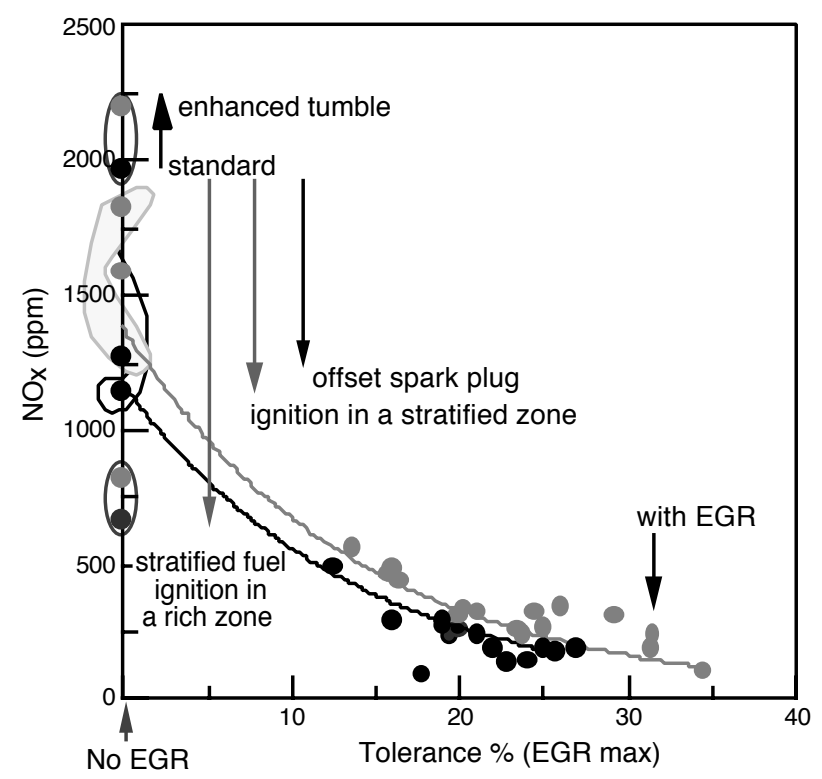

Figure 22

Effect of exhaust gas recirculation on $\mathrm{NO}_{\mathrm{x}}$ emissions/ comparison with no recirculation configurations.

a stratified zone of fuel distribution reduces $\mathrm{NO}_{\mathrm{x}}$. The lowest emissions are obtained when the gasoline is stratified while igniting in rich zone. Actually in this case $\mathrm{NO}_{\mathrm{x}}$ are created earlier and have time to recombine before exhaust valve opens. $\mathrm{NO}_{\mathrm{x}}$ emissions are further reduced by exhaust gas recirculation and decrease globally with increasing recirculation rate (Fig. 21). Points are however dispersed due to configuration differences. Configurations with a higher tolerance have not systematically lowered the $\mathrm{NO}_{\mathrm{x}}$ emissions level. For example configuration $\mathrm{D}$ which only tolerate $17 \%$ EGR has the lower emissions levels. However a low tolerance may lead to high HC emissions levels. Note that enhanced tumble decreases $\mathrm{NO}_{\mathrm{x}}$ emissions when recirculating while it increases them without: this is an important effect of dilution. The better configuration in term of $\mathrm{NO}_{\mathrm{x}}$ /tolerance trade-off is the configuration B.

To summarise, tolerance is maximised by high turbulence level, recirculating by two ducts and with a stratification of gasoline. An important reduction of $\mathrm{NO}_{\mathrm{x}}$ emissions without deterioration of $\mathrm{HC}$ emission is expected. Some configurations where visualisation showed high additional residual concentrations exhibit a good efficiency for $\mathrm{NO}_{\mathrm{x}}$ reduction. However the tolerance to recirculating may lead to high $\mathrm{HC}$ emissions level.
Pollutants emitted by the optical cylinder are questionable. The mean temperature is lower, dead volumes are more important and absorption by oil does not exist. Therefore, we decided to test the same good configurations on a conventional single cylinder head with the same geometry. Tests were made at recirculating rate accepted by all configurations: $15 \%$ at optimum spark timing. Configurations can be split into 2 groups.

The first one with $\mathrm{NO}_{\mathrm{x}}+\mathrm{HC}$ emissions lower than $5000 \mathrm{ppm}$ is the configuration with recirculating through both intake pipe. In this case the emissions are further reduced to less than $3000 \mathrm{ppm}$ by enhancing the tumble. Configuration A and B selected in the optical engine study are included in this group.

The second group is for the recirculation through only one duct for which stratification of gasoline reduces emissions to less than $6000 \mathrm{ppm}$. It was seen that stratifying gasoline leads to a natural stratification of burned gases. A high local equivalence ratio leads to a low temperature in burned gases at the maximum crank angle pressure. Stratifying burned gases slows down flame propagation at the end of combustion which is unfavourable for HC when the fuel is homogeneous because some fuel cannot burn at the end.

The diagram $\mathrm{NO}_{x} / \mathrm{HC}$ is drawn on Figure 23. It confirms that the reference configuration with no

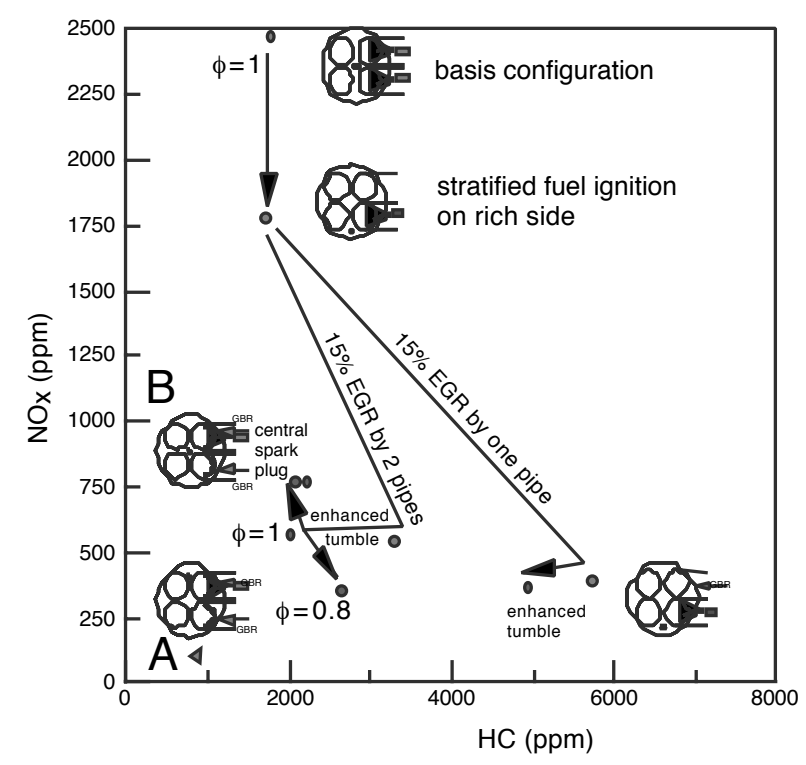

Figure 23

$\mathrm{NO}_{\mathrm{x}} / \mathrm{HC}$ diagram for conventional single cylinder. Effect of introducing $15 \% \mathrm{EGR}$ on $\mathrm{NO}_{\mathrm{x}}$ and $\mathrm{HC}$ emissions. 
The diagram $\mathrm{NO}_{x} / \mathrm{HC}$ is drawn on Figure 23. It confirms that the reference configuration with no recirculation is the worst for $\mathrm{NO}_{x}$. As found in the optical engine, one verifies that $\mathrm{NO}_{\mathrm{x}}$ reduction is achieved by stratifying the fuel with the spark on the rich side. Adding 15\% exhaust gas further reduces $\mathrm{NO}_{\mathrm{x}}$. Nevertheless this $\mathrm{NO}_{\mathrm{x}}$ reduction is always accompanied by a deterioration of $\mathrm{HC}$ which is amplified when recirculating into only one duct. Enhancing turbulence increases air/fuel/burned gases mixing stability and accelerates the flame front. This leads to reduced $\mathrm{HC}$ emissions. In the case of recirculating exhaust gases through both ducts, the enhance tumble notably compensates the $\mathrm{HC}$ deterioration.

\section{CONCLUSIONS}

A method for the visualisation of burned gases in engines, on the basis of Planar Laser Induced Fluorescence using biacetyl as a tracer is developed. The admitted fresh air is seeded with biacetyl and images of the engine charge are taken, containing the burned gases for which the biacetyl burned in the preceding cycle. Hence the intensity image of the fluorescence shows a lower signal at locations where the residual gas are present in higher concentrations. For quantification, a reference image is used, corresponding to a homogeneous charge without burned gases. The technique, which allows a normal operation of the engine (i.e., no skip-firing), gives good qualitative results for the evaluation of burned gas fractions.

The investigation of the residual gas visualisation has demonstrated that fuel, fuel distribution, flow, spark plug location and volumetric efficiencies have an important influence on their distribution. Residual gas concentration is a result of a complex combination of intake and exhaust pressure, flow motions and combustion process. We verified that the amount of residual gases by the combustion chamber decreases for configurations increasing intake pressure or decreasing exhaust pressure: volumetric efficiency influences intake pressure. The spark plug location influences the combustion process, and then the exhaust pressure especially at high charge. It was also found that the flow motion is responsible for residual concentration at spark timing, especially when the tumble is enhanced as residual gases trapped in the tumbling movement.
Finally residual gas distribution seems difficult to control because of the complexity of interaction between parameters. A solution would be to reduce residual gas and replace them by recirculated exhaust gases.

Burned gas stratification control is achieved by a combination of favourable parameter: maximum recirculation in one duct, injection of fuel in the opposite duct, and enhanced tumble. Homogeneous distribution of burned gas is obtained when recirculating exhaust gas and injecting fuel in both intake ducts or when recirculating exhaust gases and injecting fuel in the same intake duct. The higher the EGR rate, the better the distribution of burned gases can be controlled.

Tolerance to recirculation is maximised through high turbulence level, recirculating through two intake ports and stratification of gasoline. An important reduction of NOx emissions without deterioration of $\mathrm{HC}$ emission is expected. Some configurations where visualisation showed high additional residual concentrations exhibit a good efficiency for $\mathrm{NO}_{\mathrm{x}}$ reduction. However, tolerance to recirculation may lead to high $\mathrm{HC}$ emissions level.

Our conclusions have been confirmed by measurements in a conventional single cylinder head with the same geometry.

\section{ACKNOWLEDGEMENTS}

This work was sponsored by the Groupement Scientifique Moteur (Peugeot SA, Renault SA and IFP) and the Ministère français de la Recherche et de l'Industrie - Étude VPE E5 1-GSM n ${ }^{\circ} 4$. The authors wish to acknowledge V. Ricordeau for his technical support, B. Cousyn and A. Floch for fruitful discussions.

\section{REFERENCES}

1 Toda T., H. Nohira and K. Kobashi (1976), Evaluation of Burned Gas Ratio (BGR) as a predominant factor to $\mathrm{NO}_{\mathrm{x}}$. SAE Paper 760765.

2 Kijota Y., T. Akishino and H. Ando (1992), Concept of lean combustion by Barrel-stratification. SAE Paper 920678.

3 Kuwahara K., T. Watanabe, J. Takemura, S. Omori, T. Kume and H. Ando (1994), Optimization of in-cylinder flow and mixing for a center-spark four valve leanburn engine employing the concept of barrel-stratifcation. SAE Paper 940986. 
4 Deschamps B., R. Snyder and T. Baritaud (1994), Effect of flow and gasoline stratification on combustion in a 4 -Valve SI engine. SAE Paper 941993

5 Galliot F., W.K. Cheng, C.O. Cheng, M. Sztenderowicz, J.B. Heywood and N. Collins (1990), In-Cylinder measurements of residual gas concentration in a spark ignition engine. $S A E$ Paper 900485.

6 J. Stokes, T.H. Lake, M.J. Christie and I. Denbratt (1994), Improving the $\mathrm{NO}_{\mathrm{x}} /$ fuel economy trade-off for gasoline engines with the CCVS combustion system. SAE Paper 940482.

7 Tabata M., T. Yamamoto and T. Fukube (1995), Improving the $\mathrm{NO}_{\mathrm{x}}$ /fuel economy for mixture injected SI engine associated with EGR. SAE Paper 950684,
8 Lebel M. and. J.M. Cottereau (1992), Study of the effect of residual gas fraction on combustion in a SI engine using simultaneous CARS measurements of temperature and $\mathrm{CO}_{2}$ concentration. SAE Paper 922388.

9 Johansson B., H. Neij, G. Juhlin and M. Aldén (1995), Residual gas visualization with laser induced fluorescence. SAE Paper 952463.

10 Le Coz J.F., S. Henriot and P. Pinchon (1990), An experimental and computational analysis of the flow field in a four-valve spark ignition engine - Focus on cycle-resolved turbulence. SAE Paper 900056.

11 Baritaud T. and T. Heinze (1992), Gasoline distribution measurements with PLIF in a SI Engine. SAE Paper 922355.

Final manuscript received in October 1997 